\title{
Conference Paper \\ Development of Textured ITO Optical Windows for Photovoltaic Applications
}

\author{
N. Tamilselvan and Periyasamy Thilakan \\ Photon Energy Technology Laboratory, Centre for Green Energy Technology, Madanjeet School of Green Energy Technologies, \\ Pondicherry University, Puducherry 605014, India \\ Correspondence should be addressed to Periyasamy Thilakan; thilakan@hotmail.com
}

Received 3 January 2013; Accepted 30 April 2013

Academic Editors: B. Bhattacharya and U. P. Singh

This Conference Paper is based on a presentation given by N. Tamilselvan at "International Conference on Solar Energy Photovoltaics" held from 19 December 2012 to 21 December 2012 in Bhubaneswar, India.

Copyright (C) 2013 N. Tamilselvan and P. Thilakan. This is an open access article distributed under the Creative Commons Attribution License, which permits unrestricted use, distribution, and reproduction in any medium, provided the original work is properly cited.

ITO thin films were deposited on glass substrates using rf magnetron sputtering. Deposition parameters such as the rf power and the oxygen dilution to the plasma are investigated. Films deposited with an increase in $\mathrm{rf}$ power were resulting in the film preferential orientation along (100) plane. Oxygen dilution to the plasma at low $\mathrm{rf}$ power of $30 \mathrm{~W}$ was found to result in a change in preferential orientation from (100) plane to (111) plane. SEM analysis revealed a spotty surface morphology for the (100) films and a granular morphology for the (111) films. The highest transmittance was found for the oxygen diluted (111) film. The highest optical bandgap of $4.33 \mathrm{eV}$ was observed for the pure Ar deposited film. Details are discussed.

\section{Introduction}

Transparent conducting oxide (TCO) thin films have been widely investigated towards the application to solar cell fabrications due to their displayed characteristics of high optical transparency and better electrical conductivity along with environmental stability [1-3]. Basically, the optical and the electrical properties of TCOs depend solemnly on their oxidation conditions. Complete oxidation was found to promote the transparency in the UV-visible range of electromagnetic spectrum, and, in contrary, the incomplete oxidation was found to promote the electronic conductivity [4]. Hence, a careful adjustment between the oxidation and the oxygen vacancy doping paves the way for the attainment of optimum values of optical transparency with optimum electrical conductivity [5].

In this context, indium tin oxide (ITO), a wide bandgap $(>3.6 \mathrm{eV})$ degenerate semiconducting material, shows the highest value of optical transparency greater than $90 \%$, better polycrystalline structures with either (222) or (400) preferred orientation, and the lowest electrical resistivity in the order of $10^{-5} \Omega$-cm $[4,5]$. Specially, the highest possible carrier doping density in the order of $10^{21} \mathrm{~cm}^{-3}$ and the associated localization of Fermi level above the conduction band level boost the very low resistivity and high transmittance in the visible region $[6,7]$. There are various deposition techniques such as DC and rf magnetron sputtering, evaporation, spray deposition, and solution-based sol-gel used to deposit ITO films and reported the role of various deposition parameters on the resultant optical, electrical, and structural parameters [8-10]. However, the demonstrated maximum possible optical transparency around $90 \%$ with better electrical conductivity of ITO becomes the landmark limiting value that directly reduces the solar cell output to $\sim 10 \%$ upon the application to solar cell fabrication. In general, in addition to the materials properties, surface structuring is well in practice to enhance the optical absorbance by reducing the surface impacts on the optical losses of the solar cell [11, 12].

Therefore, in an alternative approach to improve the optical transmittance of ITO films, we tried to establish the surface texturing inherently during the deposition of polycrystalline films using $\mathrm{rf}$ magnetron sputtering. The results are presented here. 


\section{Experiment}

Indium tin oxide thin films with thickness in the range of 200-300 nm were deposited over glass substrate using the rf power ranging from $25 \mathrm{~W}$ to $80 \mathrm{~W}$ at an elevated substrate temperature of $250^{\circ} \mathrm{C}$ in order to maintain the crystallization as well as tin activation [13]. The sputtering was carried out using commercial ITO target composed of $90: 10 \mathrm{wt} \%$ of $\mathrm{In}_{2} \mathrm{O}_{3}$ and $\mathrm{SnO}_{2}$, respectively. The sputter targeted to substrate distance was retained constant at $5 \mathrm{~cm}$, and the ITO depositions were employed by varying sputtering parameters such as rf power density and the gas composition between Argon and $\mathrm{Ar} / \mathrm{O}_{2}$ mixture.

Deposited films were characterized using X-ray diffraction analysis, scanning electron microscopy, and UV-visibleNIR spectroscopy. UV-visible spectrophotometer measurements were further used for the analysis of absorption coefficient and optical bandgap properties of the films.

\section{Results and Discussion}

3.1. Structural Characterization. The X-ray diffraction analysis was carried out for the films deposited at different $\mathrm{rf}$ powers at a substrate temperature of $250^{\circ} \mathrm{C}$. Figure 1 shows the XRD spectra of the films deposited at different $r f$ powers. It is shown that all the films exhibit polycrystalline structure in comparable to the standard JCPDS card number 060416 for BCC cubic $\operatorname{In}_{2} \mathrm{O}_{3}$ (IO) crystal structure except the observed change in the preferred plane of orientation. According to the standard, the basic structure of indium oxide films results in the preferential plane of crystallization along (222) plane, whereas here in Figure 1 it is found that the preferential plane of crystallization is observed as (400) plane. The change in preferential plane is confirmed from the decrease in the I(222)/I(400) value less than 3.33 of the JCPDS report [8]. The value is found to decrease to 0.81 for $30 \mathrm{~W}$ and to 0.35 for $80 \mathrm{~W}$, respectively, without major changes in the peak positions. This observation is in analogous to the reported (400) preferential plane of crystallization for the films deposited with poor stoichiometric composition less than 1.5 of $\mathrm{In} / \mathrm{O}$ ratio. It is reported that the poor oxidation of ITO resulted in poor transparency and better crystallization and conductivity [5].

In order to verify the impact of oxygen stoichiometry on the film crystallization, $3 \%$ of oxygen was diluted into the Ar plasma at the deposition power of $30 \mathrm{~W}$. Figure 2, shows the XRD spectra of both films deposited with and without oxygen dilution to the plasma. It can be seen that the oxygen dilution to the Ar plasma resulted in the preferential plane of crystallization comparable to the JCPDS card number mentioned earlier. This oxygen-induced change in the preferential plane of crystallization towards the standard XRD reference states that the ITO crystallization is oxygen stoichiometrydependent as reported in [8]. The $\mathrm{I}(222) / \mathrm{I}(400)$ of the film was found to change from 0.81 to 3.94 upon oxygen dilution. This indicates that the oxygen dilution enhances the crystallization of (222) plane stronger than any other plane of crystallization, which may be related to the impact on the type

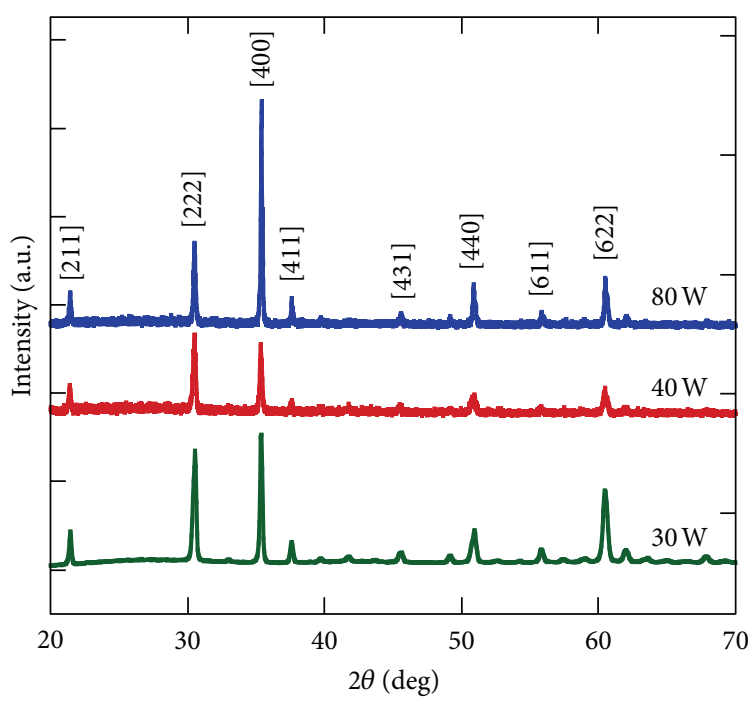

FIGURE 1: X-Ray diffraction pattern of ITO thin film sputtered at different $\mathrm{rf}$ powers and substrate temperature of $250^{\circ} \mathrm{C}$.

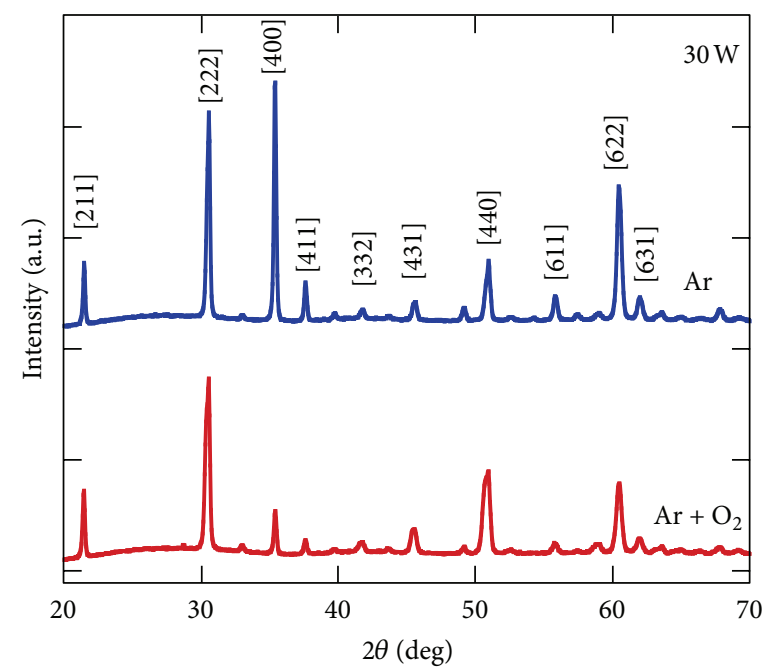

FIGURE 2: X-Ray diffraction pattern of ITO thin film sputtered at $30 \mathrm{~W}$ rf power with and without oxygen addition to the plasma.

of oxygen vacancy present in the crystallites, which revoke the habitual crystallization of ITO as reported in [5].

Crystalline sizes of the films were calculated using in Scherrer's formula along the preferential plane of crystallizations [14]. The values are found to increase from $39 \mathrm{~nm}$ to $52 \mathrm{~nm}$ along with the increase in rf power from $30 \mathrm{~W}$ to $80 \mathrm{~W}$. This increase in crystalline size along the (400) preferential plane of crystallization clearly indicates the occurrence of columnar growth along this direction of (100). On the other hand, the oxygen dilution and its correlated change in preferential plane of crystallization from (400) to (222) were found to decrease the crystalline size from $29 \mathrm{~nm}$ to $21 \mathrm{~nm}$ along the (222) direction. Hence, it is identified that the increase in $\mathrm{rf}$ power leads to the crystallization of ITO with (400) crystallization, and, on the other hand, the oxygen 


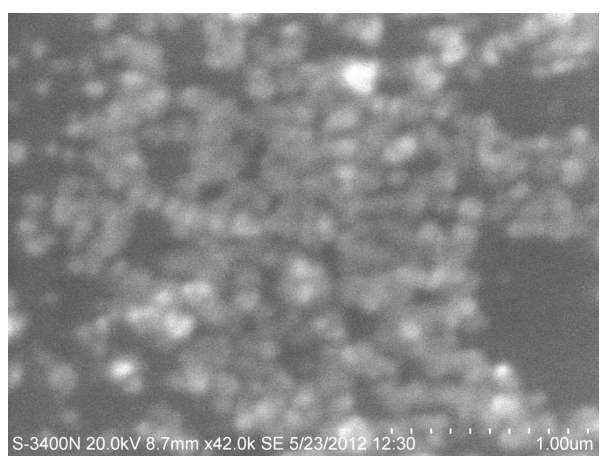

(a)

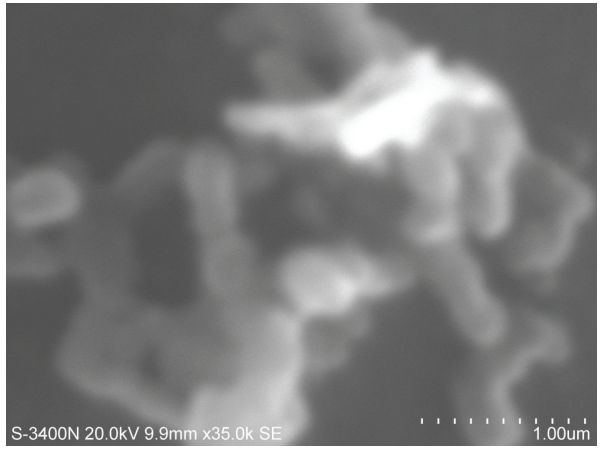

(b)

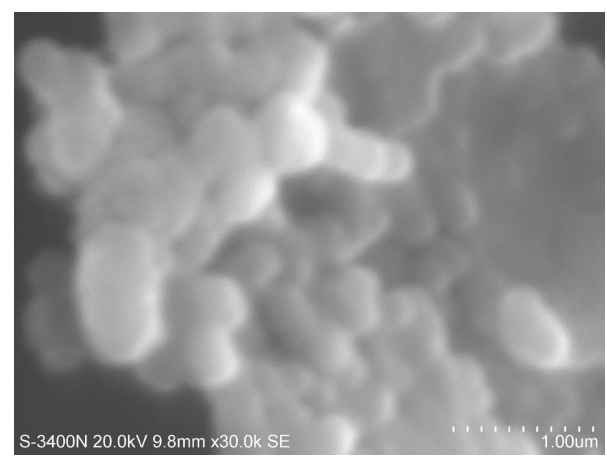

(c)

FIGURE 3: (a) SEM image of the ITO film sputtered at $\mathrm{rf}$ power of $30 \mathrm{~W}$ at $T_{s}=250^{\circ} \mathrm{C}$. (b) SEM image of the ITO film sputtered at $\mathrm{rf}$ power of $80 \mathrm{~W}$ and $T_{s}$ of $250^{\circ} \mathrm{C}$. (c) SEM image of the film deposited using $30 \mathrm{~W}$ and oxygen dilution.

dilution leads to the crystallization of ITO films with (222) crystallization.

3.2. SEM Analysis. Scanning electron microscope (SEM) was employed to analyze the surface structure of the films deposited at different rf power densities as well as with oxygen dilution.

Figures 3(a) and 3(b) show the surface microstructure of the ITO thin films. Sharp and spotty surface structure observed for the film deposited using $30 \mathrm{~W}$ of $\mathrm{rf}$ power was found to change to the grouped few larger spots. This observed less number of grouped larger spots is the evidence for the presence of high value of RMS roughness.

The SEM image of the oxygen diluted film with (222) orientation is shown in Figure 3(c). The figure shows that the films are having granular type of morphology. Hence, it is observed that the change in the preferential plane of crystallization from (400) plane to (222) plane was also found to change the surface microstructure of the rf magnetron sputtered ITO films.

3.3. Optical Characterizations. The optical properties such as the transmittance and absorbance spectra were measured using UV-visible spectrophotometer between 300 and $900 \mathrm{~nm}$. It is observed that the increase in $\mathrm{rf}$ power from $30 \mathrm{~W}$ to $80 \mathrm{~W}$ was found to decrease the overall optical transmittance from $77.5 \%$ to $60 \%$. The refractive index of the film was calculated using the relation given by [15], and Figure 4

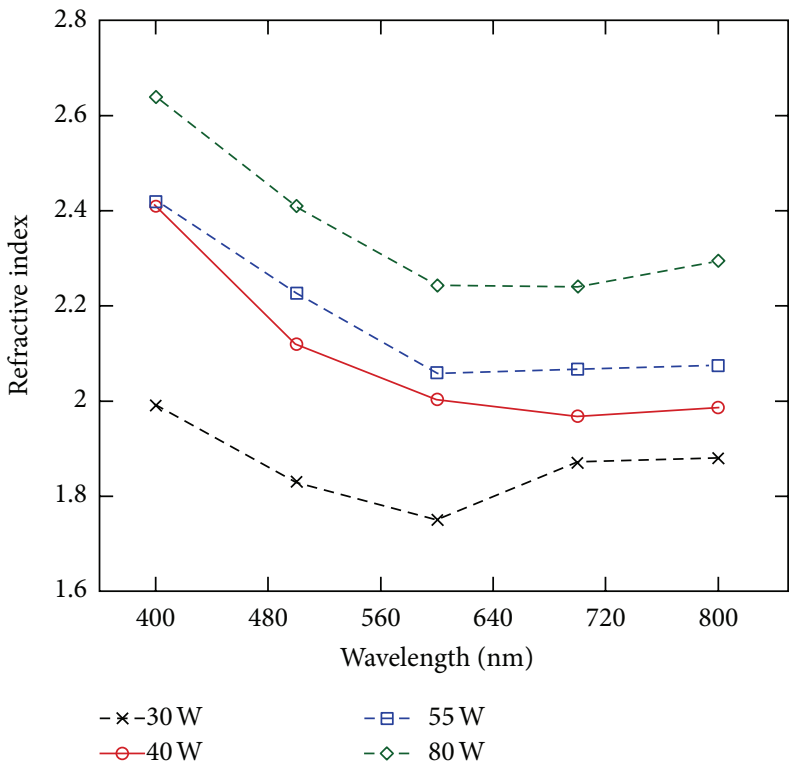

FIGURE 4: Plot wavelength-dependent refractive index of the films deposited at different rf powers.

shows the plot of wavelength-dependent refractive index of the films deposited using different rf powers.

The lowest $\mathrm{rf}$ power of $30 \mathrm{~W}$ is found to result in the highest transmittance as well as lowest refractive index. 


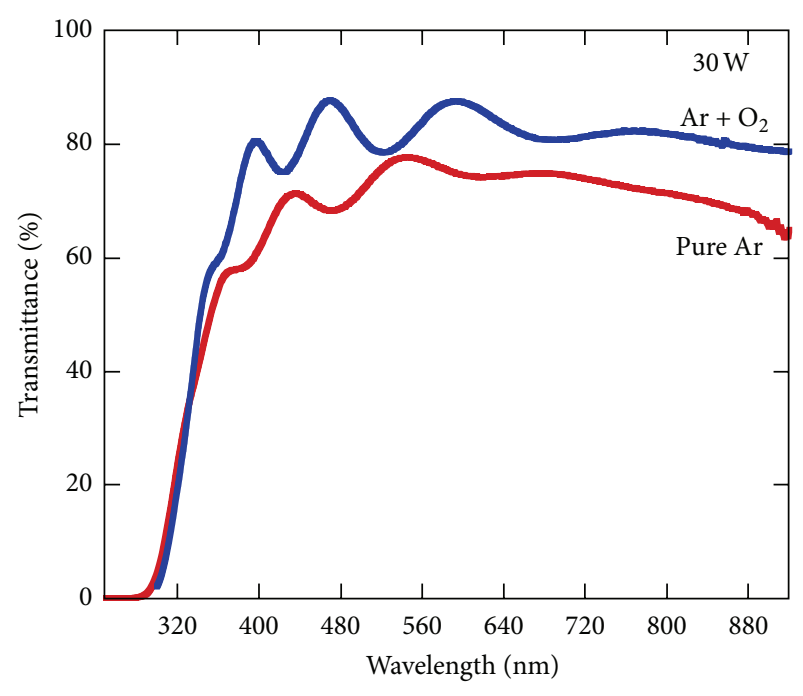

FIGURE 5: Optical transmittance spectra of ITO thin film sputtered using $30 \mathrm{~W}$ of rf power and oxygen dilution at a $T_{s}$ of $250^{\circ} \mathrm{C}$.

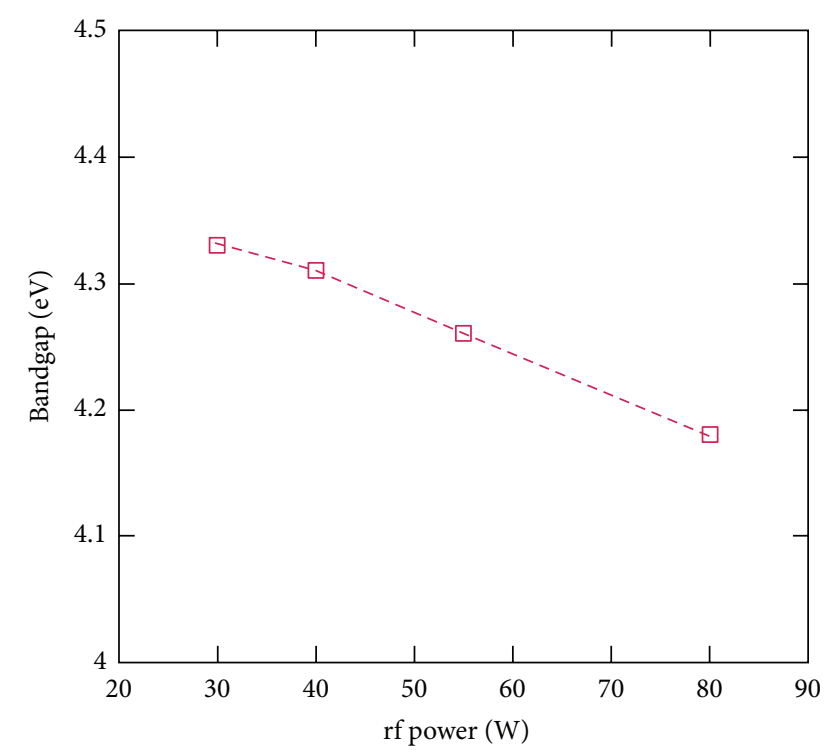

Figure 6: Plot of the bandgap values with respect to the rf power used for the deposition.

Figure 5 shows the comparative plot of the transmittance spectra of the films deposited without and with oxygen dilution at the rf power of $30 \mathrm{~W}$. The film deposited with pure Ar plasma is found to result in the maximum transmittance of $77.5 \%$. Whereas the film deposited with the same power and oxygen dilution was found to result in the transmittance of $87.58 \%$. Hence, it is clear that the oxygen dilution enhances the transmittance value in addition to the change in the preferential plane of crystallization.

Further, absorption coefficient values are calculated using the relation given by Meng and Santos [16]. Calculated values were further used to plot and analyze the band structure properties of the films. Figure 6 shows the plot of the calculated bandgap values with respect to their rf powers.
The highest bandgap of $4.33 \mathrm{eV}$ was observed for the film deposited using $30 \mathrm{~W}$ of $\mathrm{rf}$ power as shown. The oxygen dilution to the film was found to reduce the bandgap value from $4.33 \mathrm{eV}$ to $4.24 \mathrm{eV}$. This reduction is attributed to the oxidation-induced reduction in the free carrier density and its associated shift in the bandgap to the lower value in contrary to the Burstein-Moss shift effect as generally observed for the increase in carrier density [7].

\section{Conclusion}

ITO thin films were deposited on glass substrates using rf magnetron sputtering. Films deposited with an increase in rf power were resulting in the preferential orientation along (400) plane. Oxygen dilution to the plasma at low rf power of $30 \mathrm{~W}$ was found to result a change in preferential orientation from (400) plane to (222) plane. SEM analysis revealed a spotty surface morphology for the (400) films and a granular morphology the (222) films. The highest transmittance was found for the oxygen diluted (222) film. Highest optical bandgap of $4.33 \mathrm{eV}$ was observed for the pure Ar deposited film and $4.24 \mathrm{eV}$ for the oxygen diluted film. Therefore, the deposition parameters of $\mathrm{rf}$ power and the oxygen dilution are able to result in the change in the film properties as well as surface microtexture.

\section{Acknowledgments}

The authors are thankful to the Centre for Nanoscience and Technology and Central Instrumentation Facility (CIF) of Pondicherry University for their support of measurements.

\section{References}

[1] T. A. Gessert, J. Burst, X. Li, M. Scott, and T. J. Coutts, "Advantages of transparent conducting oxide thin films with controlled permittivity for thin film photovoltaic solar cells," Thin Solid Films, vol. 519, pp. 7146-7148, 2011.

[2] H. Liu, V. Avrutin, N. Izyumskaya, U. Ozgur, and H. Morkoc, "Transparent conducting oxides for electrode applications in light emitting and absorbing devices," Superlattices and Microstructures, vol. 48, pp. 458-484, 2010.

[3] I. Maksimenko and P. Wellmann, "Low temperature processing of hybrid nanoparticulate Indium Tin Oxide (ITO) polymer layers and application in large scale lighting devices," Thin Solid Films, vol. 519, no. 17, pp. 5744-5747, 2011.

[4] F.-J. Haug, R. Biron, G. Kratzer et al., "Improvement of the open circuit voltage by modifying indium-tin-oxide front electrode in amorphous n-i-p solar cells," Progress in Photovoltaics: Research and Applications, vol. 20, pp. 727-734, 2011.

[5] E. Terzini, P. Thilakan, and C. Minarini, "Properties of ITO thin films deposited by rf magnetron sputtering at elevated substrate temperature," Materials Science and Engineering B, vol. 77, no. 1, pp. 110-114, 2000.

[6] S. Sun, P. Wu, and P. Xing, " $d^{0}$ ferromagnetism in undoped n and p type $\mathrm{In}_{2} \mathrm{O}_{3}$ films," Applied Physics Letters, vol. 101, no. 13, Article ID 132417, 4 pages, 2012.

[7] C.-H. Ho, C.-H. Chan, L.-C. Tien, and Y.-S. Huang, "Direct optical observation of band-edge excitons, bandgap, and fermi 
level in degenerate semiconducting oxide nanowires $\mathrm{In}_{2} \mathrm{O}_{3}$," The Journal of Physical Chemistry C, vol. 115, pp. 25088-25096, 2011.

[8] P. Thilakan, C. Minarini, S. Loreti, and E. Terzini, "Investigations on the crystallization properties of $\mathrm{rf}$ magnetron sputtered indium tin oxide thin films," Thin Solid Films, vol. 388, pp. 3440, 2001.

[9] R. Oesterlien and H. J. Krokoszinski, "Optical dispersion in electron-beam evaporated Indium Tin Oxide thin films," Thin Solid Films, vol. 175, pp. 241-247, 1989.

[10] Y. Li, G. Zhao, Y. Ren, and D. Chen, "Microstructure analysis of sol-gel derived nanocrystalline ITO thin films," Surface and Interface Analysis, vol. 43, pp. 1199-1202, 2010.

[11] J. Kim, M. Kim, H. Kim et al., "Effective light management of three dimensionally patterned transparent conductive oxide layers," Applied Physics Letters, vol. 101, no. 14, Article ID 143904, 4 pages, 2012.

[12] T. Chih-Hung, S.-Y. Hsu, T.-W. Huang et al., "Influences of textures in fluorine-doped tin oxide on characteristics of dyesensitized solar cells," Organic Electronics, vol. 12, pp. 2003-2011, 2011.

[13] E. Terzini, G. Nobile, S. Loreti, C. Minarini, T. Polichetti, and P. Thilakan, "Influences of Sputtering Power and substrate temperature on the properties of $\mathrm{rf}$ Magnetron sputtered Indium Tin Oxide thin films," Japanese Journal of Applied Physics, vol. 38, pp. 3448-3452, 2009.

[14] D. B. Cullity, Elements of X-Ray Diffraction, Addison-Wesley, Reading, Mass, USA, 1956.

[15] M. Di Giulio, G. Micocci, R. Rella, P. Siciliano, and A. Tepore, "Optical absorption and photoconductovity in amorphous indium selenide thin films," Thin Solid Films, vol. 148, no. 3, pp. 273-278, 1987.

[16] L.-J. Meng and M. P. dos Santos, "The influence of oxygen partial pressure and total pressure $\left(\mathrm{O}_{2}+\mathrm{Ar}\right)$ on the properties of tin oxide films prepared by dc sputtering," Vacuum, vol. 45, no. 12, pp. 1191-1195, 1994. 

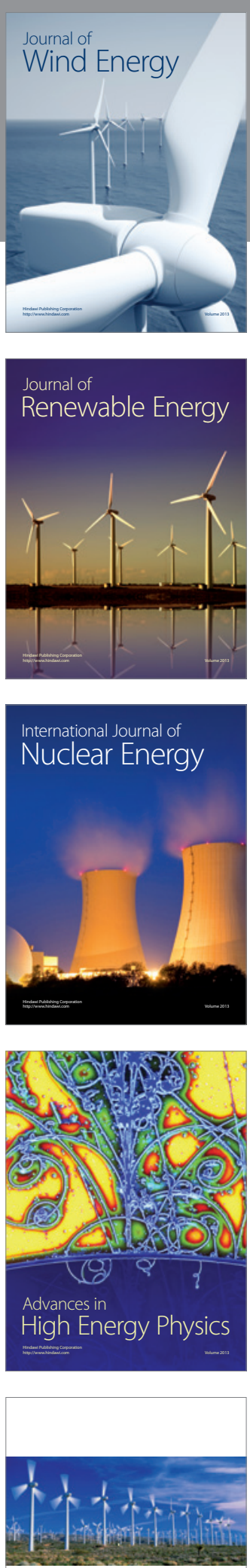

ISRN

Renewable Energy
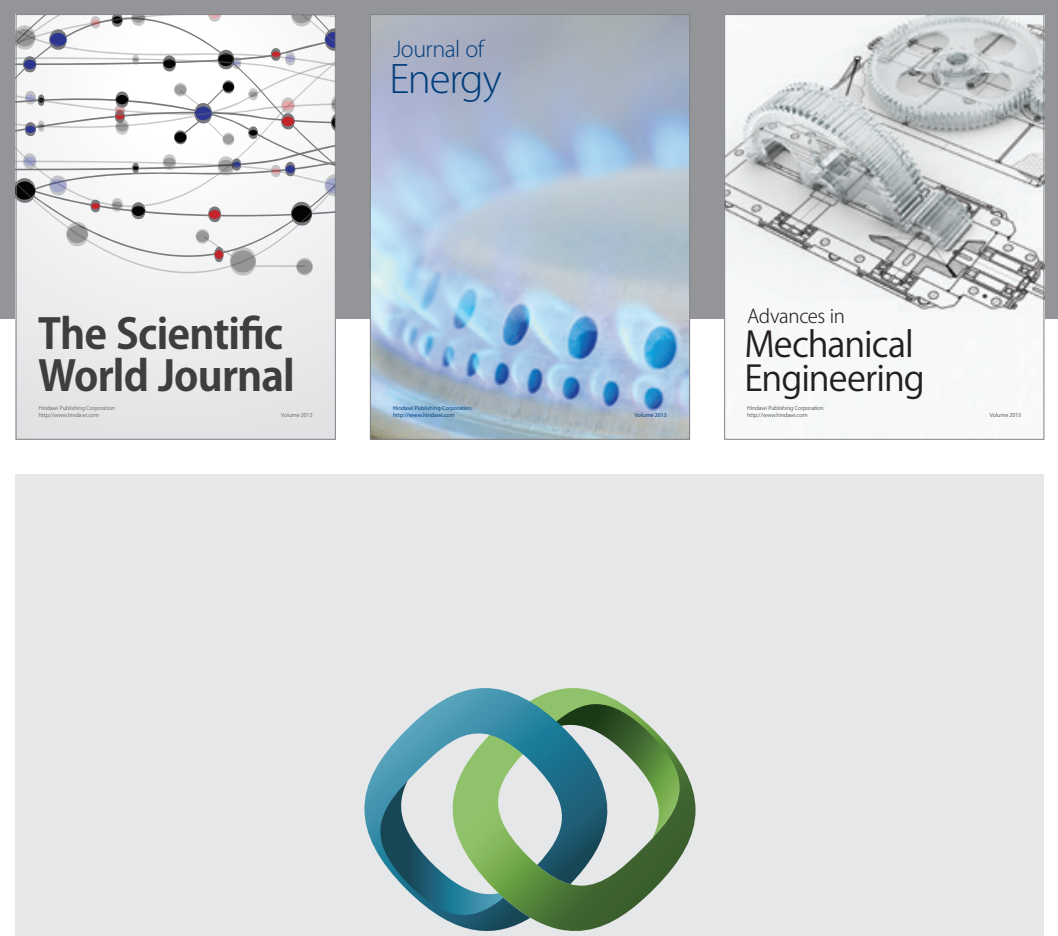

\section{Hindawi}

Submit your manuscripts at http://www.hindawi.com
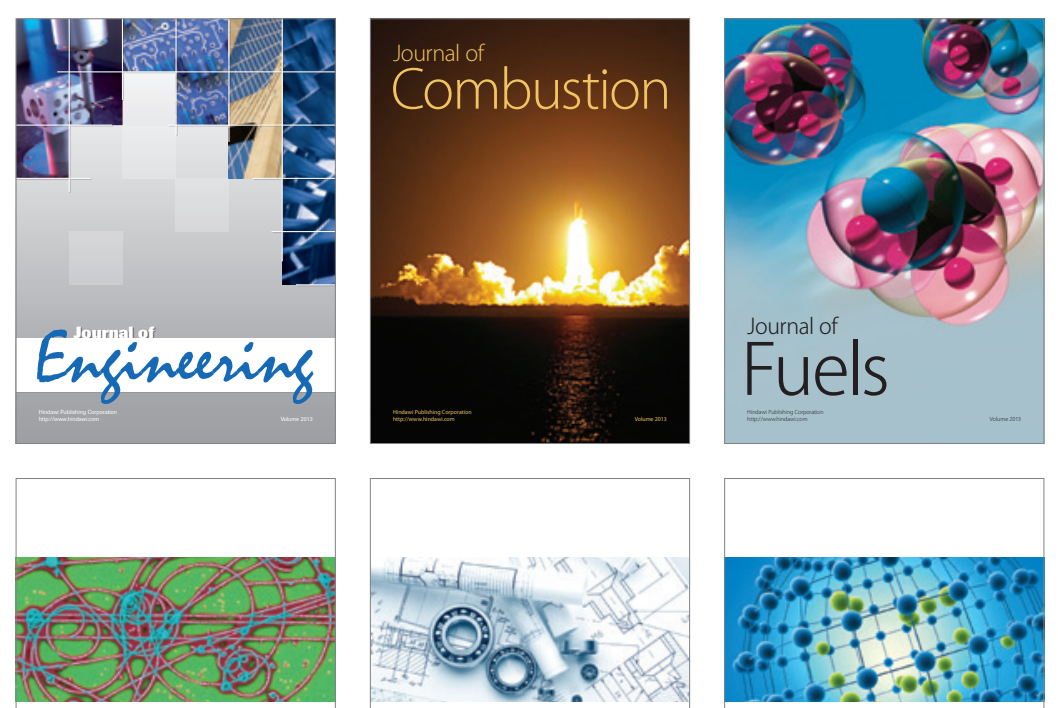

ISRN

High Energy Physics

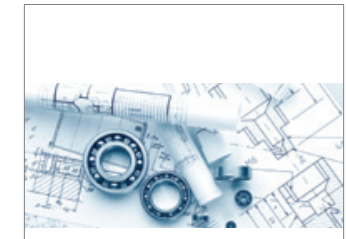

ISRN

Mechanical

Engineering

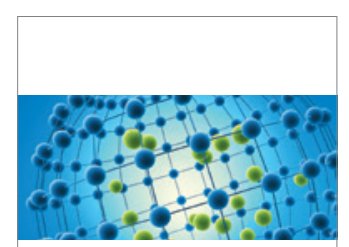

ISRN

Chemical

Engineering
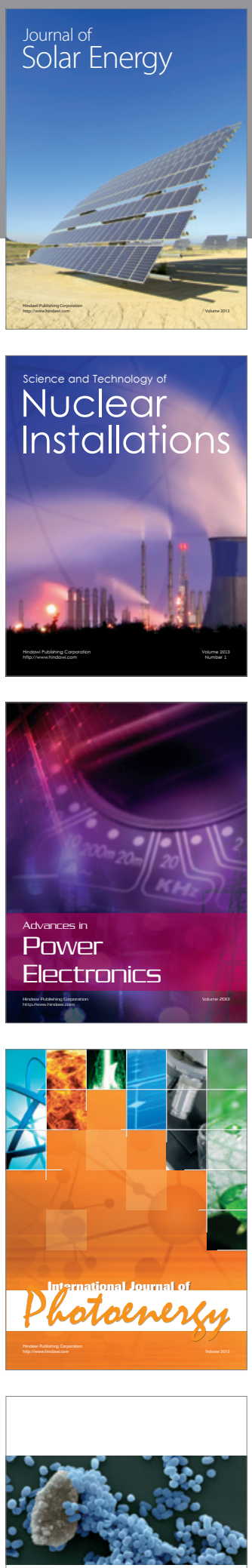

ISRN

Biotechnology 

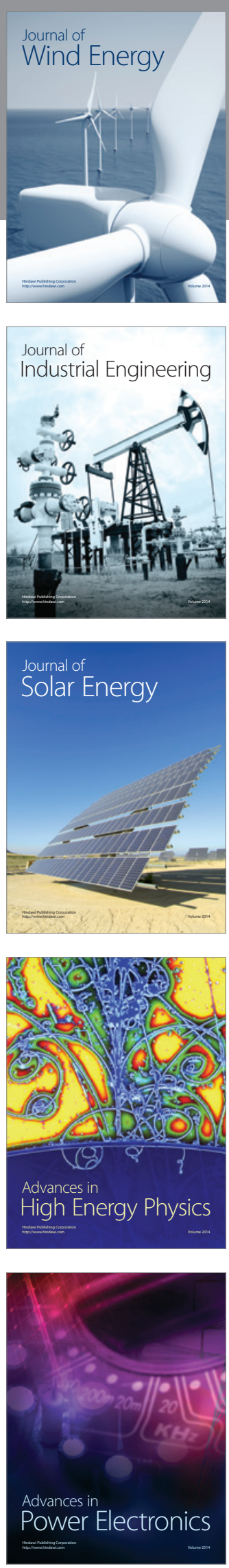
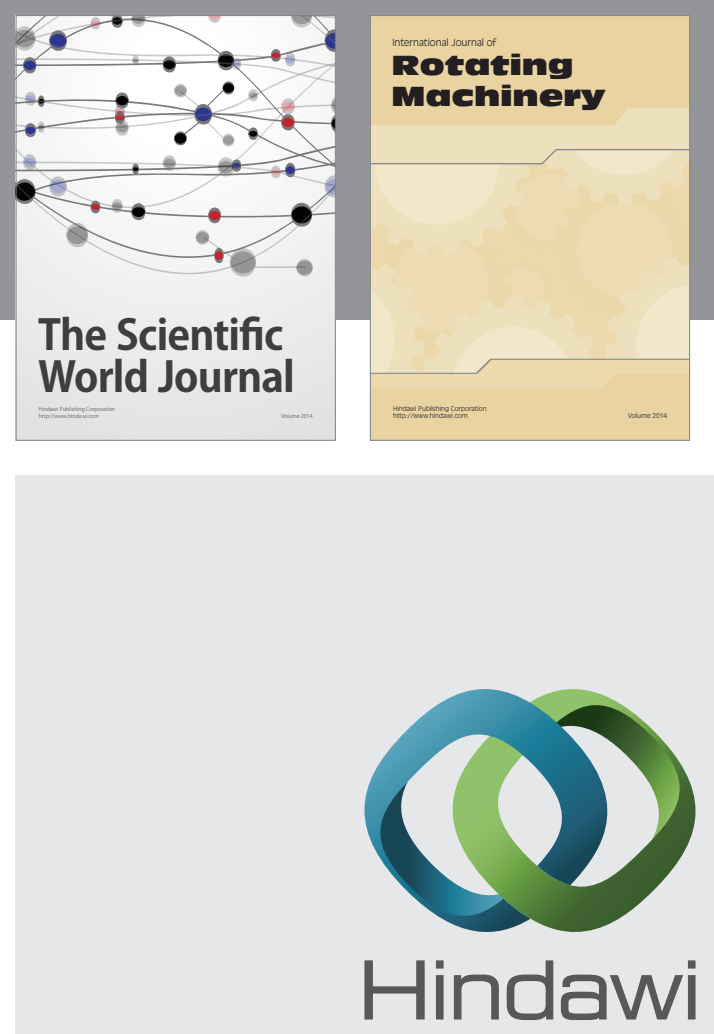

Submit your manuscripts at

http://www.hindawi.com
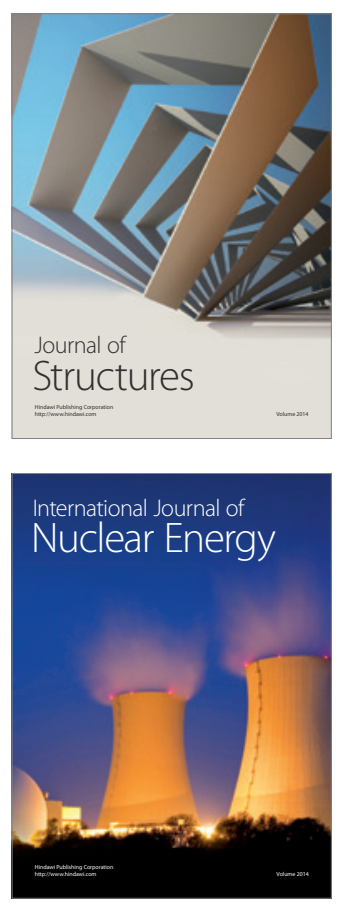
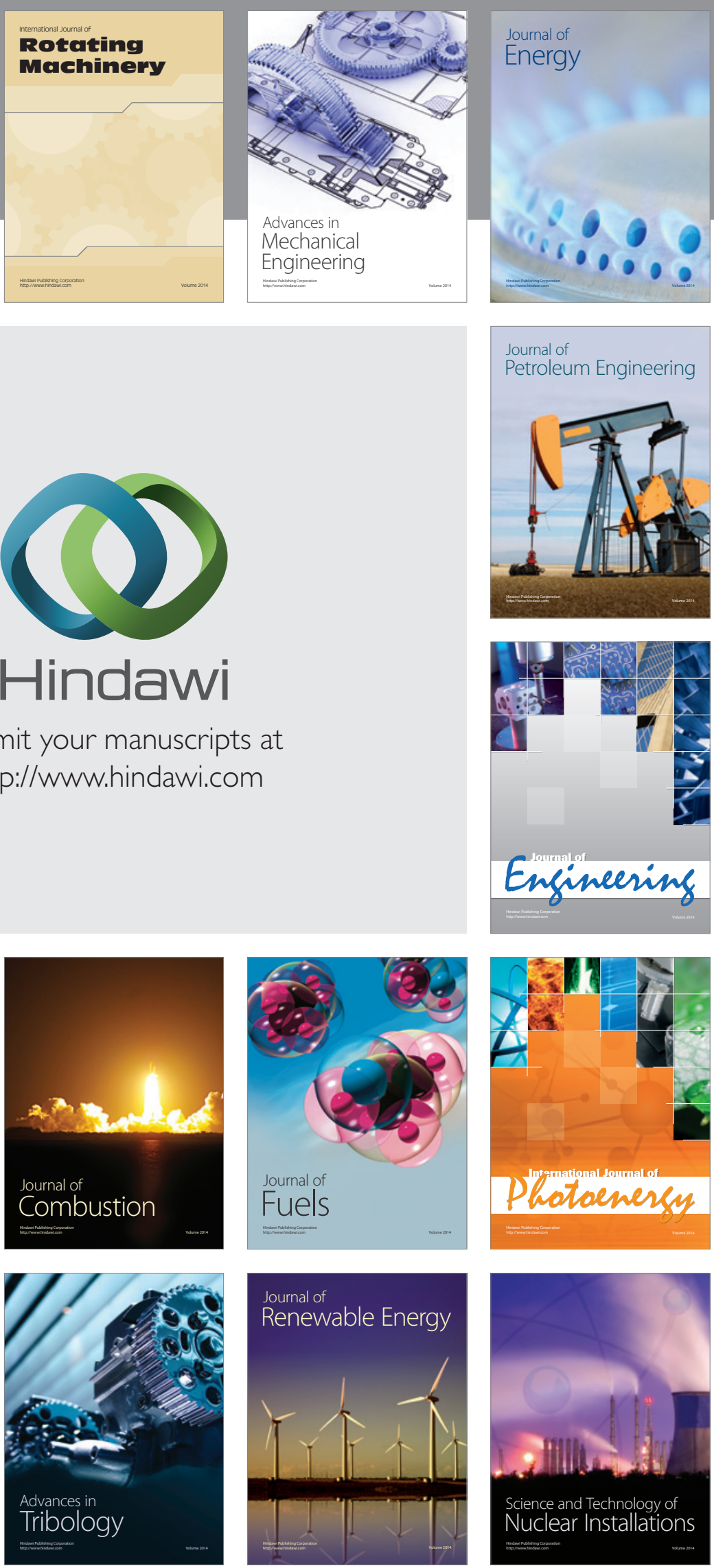